\title{
FENOMENOLOGIA DA AUSÊNCIA COMO CHAVE DE COMPREENSÃO PARA A RELAÇÃO ENTRE SER E DEIDADE A PARTIR DO PENSAMENTO DE MARTIN HEIDEGGER*
}

\section{PHENOMENOLOGY OF ABSENCE AS KEY TO UNDERSTANDING THE RELATIONSHIP BETWEEN BEING AND THE DEITY FROM THE THOUGHT OF MARTIN HEIDEGGER}

Daniel Toledo**

\begin{abstract}
RESUMO
O presente artigo tem por objetivo apresentar uma determinada forma de compreensão fenomenológica que permita estabelecer uma relação ontológica com o horizonte de sentido da deidade apoiada em sua dinâmica essencial de recuo. A referida compreensão deverá ser situada dentro do contexto de pensamento do filósofo alemão Martin Heidegger. Para tal propósito, o movimento ontológico de recuo do ser, compreendido como condição de possibilidade para a manifestação de sentido em geral, deverá ser apropriado como chave de entendimento para uma determinada modalidade de epifania divina: o movimento essencial de afastamento da deidade. Sob essa perspectiva, tentaremos delinear uma noção de transcendência a partir de uma abertura de sentido que se apresente como condição de possibilidade também para o fenômeno religioso em sua dinâmica essencial de fundo.
\end{abstract}

PALAVRAS-CHAVE: Heidegger. Ontologia. Filosofia da religião. Fenomenologia da ausência. Recuo do divino.

\begin{abstract}
The objective of this article is to present a specific phenomenological understanding that enables us to establish an ontological relation with the horizon of meaning of the deity supported in its essential dynamic of retreat. Such understanding should be situated within the context of thought of the German philosopher Martin Heidegger. For this purpose, the ontological movement of retreat of the being, understood as a condition of possibility to the manifestation of the meaning in general, should be used as the key to understanding for a given modality of divine epiphany: the essential movement of retraction by the deity. Under this perspective, we will try to delineate a notion of transcendence based on a meaning's openness that also arises as a condition of possibility for the religious phenomenon in its background essential dynamics.
\end{abstract}

KEYWORDS: Heidegger. Ontology. Religious philosophy. Phenomenology of absence. Retreat of the divine.

\footnotetext{
* Este artigo é o primeiro resultado de um pós-doutorado em andamento sob a supervisão do prof. Dr. Márcio Paiva junto a PUC Minas

** Bacharel em filosofia pela UFJF, mestre, doutor e pós-doutor na área de concentração em filosofia da religião pelo PPCIR-UFJF e pós-doutorando pela PUC Minas. E-mail: dasilvatoledo@yahoo.com.br
} 


\title{
1 Introdução
}

No "Zürcher Seminar", ministrado em 1951, quando questionado especificamente quanto a uma eventual possibilidade de identificação entre Deus e o ser em sua filosofia, Martin Heidegger responde categoricamente da seguinte maneira:

\begin{abstract}
Ser e Deus não são idênticos, e eu nunca tentaria pensar a essência de Deus por meio do ser. Alguns talvez saibam que eu provenho da teologia e compreendam que por ela ainda guardo um amor antigo. Se um dia eu escrevesse uma teologia - para o que às vezes me sinto estimulado - então nela não poderia aparecer a palavra "ser". A fé não tem por necessário o pensamento do ser. Se ela dele precisa, então já não é mais fé (HEIDEGGER, 2005b, p.436-437).
\end{abstract}

Entendemos tratar-se aqui, sobretudo, de uma restrição, e não de uma interdição. Isso fundamentalmente pelo seguinte: o fato de Deus e o ser não poderem ser identificados não significa que não possa ser pensada qualquer tipo de relação entre o ser e a deidade compreendida como espaço de manifestação da divindade, uma vez que está claro que a delimitação apontada diz respeito majoritariamente a uma determinada configuração do divino, sabidamente, aquela que é tradicionalmente devedora da constituição ontoteológica da metafísica. ${ }^{1}$

Frente a isso, a distinção a ser explorada aqui repousa na possibilidade de que, para aquém do "Deus" da tradição metafísica (judaico-cristã-helenista), possamos apontar para uma maneira de compreensão específica da "deidade" através de uma determinada relação de tensão com o pensamento ontológico-existencial. "Isto quer dizer: não se trata, sobretudo, de designar de maneira exemplar determinadas esferas ônticas, mas principalmente de tornar visíveis os modos fundamentais do ser em sua origem a partir da essência do ser: o ser do deus, o ser do homem" (HEIDEGGER, 2001b, p. 94).

Reconhecidamente, ao longo dos caminhos de pensamento de Heidegger despontam veredas que o levam a pensar sim a questão do divino a partir de uma dimensão ontológicoexistencial, seja depois ou mesmo antes da restrição apresentada de maneira introdutória. Explorando essas sendas, o que nos parece necessário então consiste em questionar justamente essa relação de tensão entre Deus e o ser através de uma chave de compreensão fenomenológica que se aproprie de maneira específica e essencial dessa tensão projetando-a

\footnotetext{
1 Além disso, o que nos parece que deve ser compreendido como uma interdição em meio a essa restrição repousaria mais especificamente no positum teológico da fé, ainda que o jovem Heidegger tenha chegado a se ocupar vigorosamente dessa questão a partir de uma perspectiva vivencial!
} 
Artigo: Fenomenologia da ausência como chave de compreensão para a relação entre ser e deidade a partir do pensamento de Martin Heidegger

como elemento relacional com uma noção de deidade que preceda determinadas configurações do divino enquanto sua condição de possibilidade.

Já cinco anos antes da afirmação inicialmente supracitada, na "Brief über den Humanismus", em resposta aos questionamentos acerca da "omissão" da "Gottesfrage" em sua analítica existencial, Heidegger, após já ter ampliado significativamente o horizonte de sentido da "Seinsfrage", assumira a seguinte delimitação:

Com a determinação existencial da essência do homem ainda nada está decidido sobre a "existência de Deus" ou seu "não-ser", como tampouco acerca da possibilidade ou da impossibilidade dos deuses. Por isso é não somente precipitado como também tacanho afirmar que a interpretação da essência do homem a partir de sua relação com a verdade do ser seria ateísmo (HEIDEGGER, 2004c, p.350-351).

E mesmo bem antes disso, apenas dois anos após a publicação de Sein und Zeit, já havia sido delimitado, em "Vom Wesen des Grundes", que

por meio da interpretação ontológica do Dasein enquanto ser-no-mundo não há decisão positiva ou negativa sobre um possível ser para Deus. Seja antes alcançado, através do esclarecimento da transcendência, um conceito mais satisfatório do Dasein, ente com relação ao qual possa ser questionado como se dá sua referência a Deus a partir de uma demanda ontológica (HEIDEGGER, 2004c, p.159).

Nesse mesmo período é sinalizada a correlação essencial entre a "transcendência do Dasein" e o "caráter negativo que pertence ao seu ser" e que determina sua condição de desamparo (HEIDEGGER, 2001, p.332-337). Referência que para ser aqui explorada deverá ser desdobrada através do seguinte percurso: num primeiro momento, apontaremos como o "não-mostrar-se" deve ser compreendido como um constitutivo fenomenológico essencial da dinâmica ontológica; em seguida, procederemos com a tentativa de evidenciar em que medida o nada, que ao mesmo tempo deve ser compreendido como suspensão do sentido último e condição de possibilidade para os fenômenos em geral, é fundamental para estabelecer um horizonte de transcendência através da abertura do ser em seu recuo abissal exigido pela diferença ontológica; por fim, aplicaremos essa chave de compreensão ao movimento de afastamento do divino compreendido também como a dinâmica essencial da deidade em geral. 


\section{0 carácter fenomenológico essencialmente negativo do sentido do ser}

O próprio sentido do ser está determinado essencialmente por uma recusa de si. $^{2}$ Isso fundamentalmente em virtude da nossa condição de finitude. ${ }^{3}$ Essa condição implica a seguinte relação: somos apenas na medida em que deixamos de ser, ao mesmo tempo em que o ser se nos dá apenas como ser do ente, isto é, restrito ao que ele não é como tal.

Nossa exposição existencial a essa abertura do ser se constitui de tal maneira que faz com que nossa inserção de mundo torne-se nosso próprio abismo (HEIDEGGER, 2003, p. 386-490). Estamos em declínio na medida em que somos consumidos por nosso próprio ser, por nossa temporalidade. E isso só se dá por não podermos nunca dar uma vazão plena, absoluta, ao sentido do ser que só se manifesta sempre como ser do ente dentro de um espaço restrito de referências e sentidos. ${ }^{4}$ Por isso é que "a manifestação do ser no tempo jamais permitirá seu desvelamento fenomenológico total" (STEIN, 2001, p.129).

Se estamos lançados em uma relação de negação acerca de nosso próprio ser, então devemos reconhecer que essa condição implica consequências diretas sobre nossa compreensão fenomenológica. Há de se observar aqui a diferença entre aquilo que se dá e o que se recolhe para que este algo se dê.

Todo e qualquer sentido atribuído ao fenômeno implica em certa medida um encobrimento da abertura de sentido que lhe é condição de possibilidade. ${ }^{5}$ Em nosso exercício de projeções das significações, estamos de saída sempre já submetidos a essa abertura sem podermos dela nos apoderar. Uma vez estando constitutivamente lançados nessa abertura que nos excede, é inevitável que toda e qualquer pretensão de totalização de sentido sucumba de maneira radical através de nosso próprio exercício existencial de compreensão dos fenômenos. O que nos escapa é então o próprio sentido do ser em sua totalidade.

O modo fundamental de ser do mortal está essencialmente determinado por sua "exposição" à abertura do ente no todo que, na medida em que se recusa, remete ao próprio abismo do ser. Isso significa o mesmo que dizer que o sentido do ser só se dá através de sua própria recusa. A presença iminente da ausência de sentido que nos expõe à perda de compreensão imediata é a mesma que com isso traz à presença o abismo do ser, tornando-nos

\footnotetext{
2 "O fundamento do ser é obscuro" (HEIDEGGER, 2005, p. 318).

3 “A finitude do ser, em cuja abertura retirante está o Da-sein do homem” (HEIDEGGER, 2005b, p. 415).

${ }^{4}$ Em "Brief über den Humanismus": "Se e como o ente se manifesta, se e como o Deus e os deuses, a história e a natureza vêm à luz na clareira do ser, se apresentando e se ausentando, isto não é o homem que decide" (HEIDEGGER, 2004c, p. 330).

5 “A abertura do ente é em si ao mesmo tempo velamento" (HEIDEGGER, 2001, p. 334).
} 
Artigo: Fenomenologia da ausência como chave de compreensão para a relação entre ser e deidade a partir do pensamento de Martin Heidegger

desamparado diante da própria abertura de mundo na qual estamos lançados (HEIDEGGER, 2004c, p.350). É dessa forma, portanto, que "a essência do ser do homem se nos abre primeiramente compreendida a partir da precariedade" (HEIDEGGER, 1998, p. 124). Essa dinâmica existencial atesta que nosso movimento de transcendência é essencialmente marcado por um deslocamento de nossa essência frente àquilo que nos excede e que ao mesmo tempo está radicado de maneira mais profunda em nossa condição última de compreensão dos fenômenos: a abertura de sentido do ser. ${ }^{6}$

Condicionado por sua finitude e tendo que, por isso, assumir sua precariedade essencial, o mortal é sustentador da possibilidade da ausência, isso significa que ele sempre traz já em seu ser um possível deixar de ser. É fundamentalmente a partir desse sentido que Heidegger (1992, p.114) irá postular que "ao ser do homem pertence um não-ser". ${ }^{7}$ E com isso, não é que Heidegger faça do homem um nada, mas antes o desvela como um manifestar do desaparecimento, o manifestar do que se esvai. Entregue ao tempo, entre o vir e o ir, o homem, em sua singularidade, oscila como aquele que constantemente desaparece. Ele é a manifestação daquilo que, sendo, é sempre já um deixar de ser. E será justamente em virtude da compreensão fundamental dessa nossa condição efêmera que a fenomenologia heideggeriana em seu todo nos ensinará de uma maneira geral que "também a ausência enquanto ausência deste desaparecer ainda é uma presença”" (HEIDEGGER, 1992, p. 117) ${ }^{8}$.

Como já sabemos, o ente só se dá através da recusa do próprio ser que lhe é condição de possibilidade. Pensada assim a partir da diferença ontológica enquanto uma espécie de sacrifício do ser, "toda apresentação em si é ao mesmo tempo ausência" (HEIDEGGER, 1992, p. 117). Essa dinâmica fundamental do ser determina que tudo aquilo que é tende, desde o primeiro momento, isto é, desde a sua origem no tempo, a deixar de ser. É essa espécie de movimento para o declínio, compreendido através desse tipo de oscilação ontológica, que determina que o ser habite o homem ao mesmo tempo dele se distanciando. Por isso é que o mortal em sua essência pertence ao sacrifício de seu próprio ser, pois a sua pertença ao ser depende fundamentalmente de uma confrontação irrevogável com o mesmo.

\footnotetext{
6 "Não é possível ao homem assegurar-se por completo do fundamento da sua própria existência" (MORUJÃO, 2000, p. 190).

7 "Este não-ser deve ser compreendido como o modo de ser mais imediato do Dasein" (HEIDEGGER, 1967, p. 176).

8 Tratar-se-ia de uma "fenomenologia do inaparente" (HEIDEGGER, 2005b, p.399-417).
} 


\section{O nada como condição fenomenológica de transcendência}

Em linhas gerais, o problema fundamental do sujeito moderno, para Heidegger, é que este construto, no fundo, isto é, no exercício mais radical de sua subjetividade, a objetivação, precisa tornar presente o ente para que do mesmo possa se assegurar através de suas representações. Esse sujeito transcendental torna-se assim a fonte doadora de sentido para tudo aquilo que é, ou seja, para todo o fenômeno que se manifesta. Constituído através da figuração metafísica da essência humana, esse processo é "o que se pode chamar de a transcendência", conforme indicado em "Zur Seinsfrage" (HEIDEGGER, 2004c, p. 397). Em contrapartida, o que Heidegger faz é procurar apontar para um sentido renovado de "transcendência", a saber, aquele através do qual o ôntico deve remeter ao ontológico como sua condição de possibilidade, de tal forma que os entes se revelem como fenômenos devedores da abertura do ser como sua condição mais radical (HEIDEGGER, 2001, p.207210), remetendo assim o ente ao que ele não é como sua condição de fundo, que como tal não pode ser objetivada, a compreensão abre para o abismo de sentido do ser:

[...] o que se passa então com isto que é totalmente outro em relação aos respectivos entes, com isto que não é um ente? Com isso se mostra que o Dasein do homem está "suspenso" neste nada, no totalmente outro em relação ao ente. Dito de outra forma, isto significa, e só poderia significar, que "o homem é aquele que guarda lugar para o nada”. A proposição quer dizer que o homem mantém aberto o espação para aquilo que é totalmente diferente do ente, de tal forma que nessa abertura possa haver (ser) algo presente (HEIDEGGER, 2004c, p. 418-419).

No mesmo ano da publicação de sua "Hauptwerk", isto é, em 1927, através de uma conferência intitulada "Phänomenologie und Theologie", Heidegger estabelece categoricamente a seguinte demarcação crítica: "Fenomenologia é sempre somente a distinção para o procedimento da ontologia, que se distingue essencialmente de todas as outras ciências positivas" (HEIDEGGER, 2004c, p. 66-67). Em um curso do mesmo ano, ele retoma tal diferenciação a fim de explicitar de maneira ainda mais acurada o fundamento da mesma, através basicamente do seguinte postulado: as ciências positivas se ocupam com as dimensões entitativas da realidade, ao passo que, frente a isso, cabe à fenomenologia indagar pelo nãoente. É nesse ponto crucial que a ontologia e a fenomenologia se entrelaçam, pois o que escapa ao ente é o ser enquanto sua condição de possibilidade. Tal ponto de contato é ainda mais significativo em virtude de ser através do mesmo que o nada, enquanto dimensão que foge ao ente e que, assim, se coloca em uma relação essencial com o ser pensado a partir de 
Artigo: Fenomenologia da ausência como chave de compreensão para a relação entre ser e deidade a partir do pensamento de Martin Heidegger

sua condição de abertura, deve ser compreendido não mais como um espaço de anulação de sentido, mas agora como uma dimensão de ressignificação na qual se recolhem os sentidos possíveis para o mundo fenomênico:

\begin{abstract}
Além deste ente, nada é. Talvez ente algum é além do contabilizado, mas talvez se $d \hat{e}$ algo ainda que na verdade não é, mas que, não obstante, se dá em um sentido ainda a ser determinado. Mais ainda. No fim há algo que precisa se dar para que se nos torne acessível o ente enquanto ente, com o qual possamos nos relacionar, algo que na verdade não é, mas que deve se dar para que possamos ter a experiência e a compreensão de algo assim como o ente em geral. Podemos atingir o ente como tal, como ente, somente se a um só tempo compreendemos o ser (HEIDEGGER, 2005, p. $13-14)^{9}$.
\end{abstract}

É neste sentido fundamental que, conforme afirmado em "Zur Seinsfrage", "a essência do nada pertence ao ser” (HEIDEGGER, 2004c, p. 414). A própria essência do „Dasein“ foge à sua apreensão imediata, não evidentemente por estar radicada em uma instância para além do sensível, mas porque sua própria condição de possibilidade, isto é, a abertura do ser a partir da qual ele está lançado no mundo, lhe é inacessível na medida em que não pode ser objetivada como tal (HEIDEGGER, 2005b, p. 345). Temos, assim, o fundamento originário de nossa essência no que nos excede e escapa. Daí que, ao se perguntar, na "Einleitung zu 'Was ist Metaphysik?'”, o que significa "existência", Heidegger a estabelece como a exposição à "abertura do ser", que alcança sua maior radicalidade no "ser para a morte" (HEIDEGGER, 2004c, p. 374).

O mortal só atinge sua totalidade tão logo se choca com os limites que lhe são constitutivos. Desse modo, ele é somente na medida em que sendo já sempre nega seu poderser em sua totalidade. Logo, relacionamo-nos com o ser somente enquanto não o apreendemos em sua totalidade. Em virtude das ausências de determinadas causas primeira e última para o ser, estar lançado no mundo significa sempre já girar em torno de um não-lugar do qual se parte e ao qual estamos destinados enquanto existimos. É nesse sentido fundamental que o nada é um constitutivo originário de nossa própria essência em seu exercício de transcendência:

\begin{abstract}
Somente em virtude da abertura originária do nada pode o Dasein do homem ir ao encontro do ente e a ele atender. Tão logo, porém, o Dasein, segundo sua essência, se relaciona com o ente que ele não é e também com o ente que ele próprio é, ele, como tal, já provém do nada manifesto. Da-sein significa: estar contido no nada. Mantendo-se no nada, o Dasein já está para além do ente no todo. Este estar para
\end{abstract}

\footnotetext{
${ }^{9}$ No "Seminar in Le Thor 1969": "O nada não é mera negação do ente. Ao contrário, o nada, em seu nadificar, nos remete ao ente em sua abertura. O nadificar do nada 'é' o ser" (HEIDEGGER, 2005b, p. 361).
} 
além do ente, designamos transcendência. Se o Dasein, no fundamento de sua essência, não transcendesse, o que agora significa, se de antemão não se mantivesse no nada, então ele nunca poderia se relacionar com o ente, como tampouco consigo mesmo. Sem a abertura originária do nada, não há autonomia e nem liberdade (HEIDEGGER, 2004c, p.114-115).

Uma vez estabelecida essa dinâmica ontológica de fundo, torna-se inevitável seu correlato existencial:

o ser-aí é finito porque sua abertura é, ao mesmo tempo, velamento; porque sua transcendência mergulha, ao mesmo tempo, na faticidade e na decaída; porque manifesta o ser sempre ligado ao nada. $\mathrm{O}$ ser é finito porque se revela na abertura do ser-aí, porque se mostra na transcendência do ser-aí e porque é sempre experimentado como o nada (STEIN, 2001, p.46).

\section{Fenomenologia e epifania da ausência}

Por mais que a questão de Deus tenha ficado de fora do rol temático de sua "Hauptwerk", Heidegger, no mesmo ano da publicação de Sein und Zeit, já se sentira compelido a tratar de tal questão, que dá ensejo à conferência "Phänomenologie und Theologie". A delimitação fundamental lançada nessa ocasião repousa na necessidade de diagnosticar o grau de positividade da teologia em uma sua eventual relação com a fenomenologia. A admissão mais importante, lançada logo de saída, é a seguinte: as ciências positivas ou ônticas, junto às quais Heidegger inicialmente situa também a teologia em sentido tradicional, pertencem à compreensão ontológica, que se recolhe em seu fundo (HEIDEGGER, 2004c, p.50). Porém, ao questionar a positividade da teologia, Heidegger, ao que parece, ainda um tanto quanto preso aos trabalhos de sua juventude, concentra-se nesse momento mais na fé que torna possível a experiência religiosa, sem voltar-se tanto para o Deus que tornaria possível essa experiência. Não obstante, tal restrição já não o impedira de entrever a necessidade de se pensar uma concepção de divindade que não se deixasse encerrar como objeto de uma investigação positiva. Diante disso, acreditamos que nos cumpre indagar por esse espaço de manifestação do divino que não se restrinja ao aspecto meramente objetivável, condicionado a determinadas apreensões substancialistas de um Deus definido através de suas propriedades ônticas (HEIDEGGER, 2005, p. 210). ${ }^{10}$

Pois bem, entre o postulado da vivência religiosa como um aspecto fundamental da dimensão existencial e o interdito de Deus tornado um positum, o que se alcança

\footnotetext{
${ }^{10}$ Em "Brief über den Humanismus": "Este vale como o ente supremo no sentido de primeira causa de todos os entes. Deus é pensado como esta primeira causa" (HEIDEGGER, 2004c, p. 350).
} 
Artigo: Fenomenologia da ausência como chave de compreensão para a relação entre ser e deidade a partir do pensamento de Martin Heidegger

explicitamente em termos de filosofia da religião "é a relação de Deus em geral com o homem como tal, e vice-versa" (HEIDEGGER, 2004c, p.59). ${ }^{11}$ Entrementes, é reconhecido que essa relação, que deve agora ser compreendida mais em nível existencial do que metafísico, implica inevitavelmente uma determinada forma de apreensão que, justamente por se chocar com o inapreensível como tal, conduz a própria compreensão aos seus limites. "Se assim não for, a inapreensibilidade, de certa forma, permanece muda" (HEIDEGGER, 2004c, p. 62). O que deve ser buscado, por conseguinte, é a dimensão prévia ou a abertura de sentido que possibilita essa confrontação.

Podendo e devendo ser também a divindade compreendida a partir dessa abertura de sentido do fenômeno que excede o mortal, a sua condição não pode ser apresentada em sua mais profunda radicalidade sem uma referência fundamental à dimensão da deidade. ${ }^{12}$

Como vimos, o próprio sentido do ser é colocado em suspenso por uma ausência que desloca, como um sinal frágil que, em vez de apontar para um determinado conteúdo, indica a precariedade de todo e qualquer sentido. As referências fáticas tornam-se provisórias ou instáveis, oscilantes. Correlativamente, o principal desafio agora repousa no seguinte: se já é sabido que para que todo e qualquer fenômeno se dê, "o ente precisa, primeiramente, ser arrancado de sua condição de velamento" (HEIDEGGER, 2001, p. 79)13), e se a divindade agora não mais pode ser entificada a fim de não reincidir na famigerada imiscuição ontoteológica da velha tradição metafísica, como repensar a possibilidade de manifestação do divino através dessa forma de compreensão fenomenológica?

Nossa hipótese é a de que a dinâmica essencial de recuo ou velamento do sentido do ser, fundamental para a compreensão ontológica, também é determinante para a compreensão que podemos ter do divino. ${ }^{14}$

A partir dessa nossa chave de leitura aqui proposta, essa dinâmica fenomenológica não poderá ser compreendida em termos de uma pretensa anulação do horizonte de sentido religioso, mas antes como um fato que exige uma significativa reapropriação do mesmo, posto que será justamente o próprio recuo da divindade que preservará a possibilidade de sua

\footnotetext{
11 "Todos os conceitos teológicos abrigam necessariamente em si $a$ compreensão do ser que o Dasein humano enquanto tal tem a partir de si, tão logo ele em geral exista" (HEIDEGGER, 2004c, p.63).

12 "O que significa o manifestar do deus? A abertura do ser" (HEIDEGGER, 2004b, p.125).

13 "Com o revelamento já vai necessariamente junto o velamento" (HEIDEGGER, 2001, p. 213); ainda (HEIDEGGER, 2004, p. 43).

${ }^{14}$ Em "Brief über den Humanismus": "A proximidade do ser. Nesta proximidade realiza-se, quando de algum modo, a decisão se e como o Deus e os deuses se recusam e a noite permanece, se e como o dia do sagrado alvorece, se e como, no despontar do sagrado, pode recomeçar uma manifestação do Deus e dos deuses" (HEIDEGGER, 2004c, p. 338).
} 
relação de tensão com os homens. O que, por sua vez, só poderá ser feito de maneira profunda se recorrermos ao jogo da verdade do ser, ou seja, à dinâmica entre velamento e revelamento. Pois é desse modo que "Deuses e homens recebem suas distintas essências do próprio ser, ou

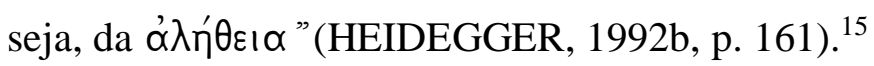

Somente após a descoberta de que o velamento é a mais radical condição de possibilidade para a compreensão do sentido do ser é que Heidegger pôde de fato levar a experiência do pensar aos seus mais extremos limites. ${ }^{16}$

Ao avançar ainda mais com sua compreensão dessa abertura de sentido que excede o plano ôntico, Heidegger não pôde deixar de conduzi-la ao encontro do horizonte daquela concepção de deidade que, justamente por não se deixar restringir ao entitativo, se manifesta somente se retraindo ${ }^{17}$.

Ao se revelar assim como o que se recolhe no abismo do ser, a deidade exigirá do pensamento um recuo, uma reserva diante do fato de que nenhuma atribuição entitativa pode determiná-la. Com isso, aquela nossa precariedade existencial, que nos é essencialmente constitutiva, deve mostrar-se em íntima conexão com esse caráter fugaz da divindade, posto que o velamento da deidade, sustentado pela verdade do ser, tornará infundado para o "Dasein" o mundo em sua abertura de possibilidades.

A divindade só pode manifestar seu sentido no tempo, o que significa: sempre somente em relação com o mortal condicionado ao seu horizonte de finitude. Por isso ela de forma alguma pode ser algo determinado de maneira apriorística e absoluta. Inserida em uma dinâmica relacional com o mortal, a deidade será apreendida somente a partir do próprio horizonte de finitude.

Sendo o deus "nada mais do que tempo", e sendo tempo a realização do devir no próprio perecer, o divino pode apenas devir, integralmente, mediante a sua retração. A retração do divino exprime essa "infidelidade divina" enquanto o que há de melhor a ser preservado, pois é ela quem aclara, com maior nitidez, a totalidade de um deus (CAVALCANTE apud HÖLDERLIN, 1994, p. 15).

\footnotetext{
${ }^{15}$ Em "Brief über den Humanismus": "O sagrado, porém, que primeiramente é somente o espaço essencial da deidade, o mesmo que, por sua vez, apenas garante a dimensão para os deuses e para o Deus, ele então vem a se manifestar só quando antes e em longa preparação o próprio ser se iluminou e teve sua experiência realizada por meio de sua verdade" (HEIDEGGER, 2004c, p. 338-339).

${ }^{16}$ Em "Brief über den Humanismus": "Contudo, enquanto a verdade do ser não é pensada, permanece toda a ontologia sem seu fundamento" (HEIDEGGER, 2004c, p. 357).

17 "O deus se manifesta essencialmente somente na medida em que se vela" (HEIDEGGER, 1996, p. 169-170).
} 
Artigo: Fenomenologia da ausência como chave de compreensão para a relação entre ser e deidade a partir do pensamento de Martin Heidegger

A recusa da deidade, que em sua manifestação escapa ao homem, abre para o próprio abismo do ser. ${ }^{18}$ Logo, o fato de a divindade nos escapar radicaliza ainda mais o caráter de precariedade do nosso ser. Essa modalidade epifânica calcada na reserva de si aproxima-se em muito da fenomenologia apoiada na diferença ontológica. ${ }^{19}$ Nessa linha de entendimento, a deidade não determina a realidade, ao contrário do que comumente se entende, mas remete ao infundado do ser enquanto abertura mais radical das possibilidades.

Colocados em jogo a partir da suspensão do sentido último, a divindade e os mortais entram em uma relação de compreensão através de uma recusa fundamental. A ausência do divino abre para a experiência da própria precariedade do mortal desamparado diante do abismo do ser. É nesse sentido que, em última instância, a deidade pode dar-se a conhecer de maneira essencial somente ao modo da privação. Na medida em que se perfaz como ausente, a divindade desloca o mortal para a experiência da privação de sentido último.

Relacionando-se através de seus limites, divinos e mortais se recolhem no mistério do ser pensado em sua diferença, isto é, enquanto renúncia a um fundamento último. Os deuses se manifestam na medida em que se recusam em sua essência, ou seja, a partir do jogo entre velamento e revelamento. A ausência do deus deixa o homem desamparado acerca de sua própria necessidade de realização dos valores absolutos. ${ }^{20}$ Isso implica, de maneira fundamental, que, "para o homem, exceder os deuses é soçobrar na profundeza abissal da verdade do Ser" (BRITO, 1999, p. 146). Pois na medida em que se chocam contra os seus limites, os mortais têm sua precariedade desvelada como tal. Essa precariedade revela ao mortal a impossibilidade de uma apropriação direta daquilo que lhe excede. Por isso é que a proximidade com o divino em seu caráter excessivo só se viabiliza em uma familiaridade com o retiro dos deuses, uma aproximação acerca do seu distanciamento preservado como tal, posto tratar-se originariamente do "deus que se retira a fim de não se perder ele mesmo como divino numa familiaridade excessivamente estreita com os mortais" (DASTUR apud HÖLDERLIN, 1994, p. 184).

\footnotetext{
${ }^{18}$ Em "Brief über den Humanismus": "O 'ser' - não é Deus e nem um fundamento de mundo" (HEIDEGGER, 2004c, p. 331).

${ }^{19}$ Em "Nietzsches Wort 'Gott ist tot"': "Contudo, em cada ocultar-se já rege ao mesmo tempo um manifestar-se" (HEIDEGGER, 1980, p. 248).

${ }^{20} \mathrm{Em}$ "Brief über den Humanismus": "Na medida em que o pensar dessa forma diz a verdade do ser, ele já está confiado ao que é mais essencial do que todos os valores e respectivos entes” (HEIDEGGER, 2004c, p. 352).
} 


\section{Conclusão}

Em “Zur Seinsfrage”, Heidegger afirma que "recusa e retiro não são, contudo, nada. Eles se impõem quase que opressivamente para o homem" (HEIDEGGER, 2004c, p. 407). O recuo do ser não se deixa apreender pelo mortal justamente por ser antes determinante para sua própria condição ontológica mais radical, a saber, aquela que delimita sua finitude essencial. Por estar originariamente projetado nessa falta de fundamento de si, "pensada corretamente a partir da 'existência', a 'essência do Dasein deixa-se pensar naquela abertura na qual o próprio ser se anuncia e se vela, se preserva e se retira, sem que esta verdade do ser se esgote no Dasein ou sequer se deixe com ele confundir" (HEIDEGGER, 2004c, p. 373374). Esta precariedade é a mesma que circunscreve a relação do mortal com seu próprio horizonte de transcendência; isso de tal forma que é justamente também essa precariedade que "se vela na ausência da presença do divino" (HEIDEGGER, 2002, p. 232). Tal precariedade, todavia, não deve ser confundida com um estado miserável, pois ela é, antes ao contrário, o índice de uma plenitude radical de sentido abissal, posto que esse espaço aberto por uma presença que se recusa como tal revela-se como uma fonte inesgotável de possibilidades que dela advém e nela se recolhe, constituindo assim o sentido renovado de transcendência que radicaliza a própria remissão ôntico-ontológica. Remetida a essa dimensão em aberto, a própria pergunta pelo sentido do ser se choca com um horizonte que lhe excede em significância, dado que através dela o não-ente apresenta-se como a instância pré-ontológica mais radical. Daí não ser coincidência que foi através da "precariedade da falta de 'nomes sagrados"” ("Not des Fehls 'heiliger Namen"”) que Heidegger chegou à seguinte constatação:

\footnotetext{
Contudo, enquanto nos for vedada a visada para o fato de que e como também no recuo e na reserva predomina um modo próprio de apresentar-se, permanecemos cegos e insensíveis pela presença que urge, que torna própria a falta, que abriga e ao mesmo tempo vela em si o nome do sagrado. Apenas um repouso na região aberta, a partir da qual se apresenta a falta, garante a possibilidade de uma olhada naquilo que hoje é, na medida em que falta (HEIDEGGER, 2002, p. 235).
}

Logo, quando falamos em ausência de sentido último, não aludimos à falta de toda e qualquer referência de mundo, mas à imposição da suspensão de determinações absolutas do próprio ser-no-mundo diante do nada para o qual está voltado seu próprio ser finito que tem no abismo do ser seu fundamento. ${ }^{21}$ Assim compreendida, a ausência de sentido é plena de

\footnotetext{
21 Em "Brief über den Humanismus": "Caso deva o homem, porém, ao menos uma vez se encontrar na proximidade do ser, então ele precisa antes aprender a existir no inominável” (HEIDEGGER, 2004c, p. 319).
} 
Artigo: Fenomenologia da ausência como chave de compreensão para a relação entre ser e deidade a partir do pensamento de Martin Heidegger

pura significância, posto que abre para a necessidade de assumirmos nossa condição essencial com a qual temos de nos confrontar enquanto lançados nessa abertura de mundo que nos excede. Correlativamente, diante do "deus que falta", o que resta é "o perdurar na ausência de deus" (HEIDEGGER, 2004b, p.86). ${ }^{22}$

Trazer sobre si sua própria incapacidade do fundamento último exige "ser forte o suficiente para realizar a experiência da negação do próprio ser" (HEIDEGGER, 2003, p. 267). ${ }^{23}$ Realizar essa experiência da negação não significa suprimi-la, mas sim reconhecê-la como essencialmente constitutiva.

A própria necessidade de resolução de nosso ser-no-mundo pressupõe uma confrontação com a nossa destinação para o declínio. Não obstante, essa condição nunca pode impugnar por completo "a existência resoluta" (HEIDEGGER, 1967, p. 299). Pelo contrário, mantém-se preservada a possibilidade de uma "de-cisão" (Ent-scheidung) "pelo ser contra o nada e, inclusive, uma dissensão com a aparência” (HEIDEGGER, 1998, p. 128). Devemos, dessa maneira, manter preservada uma determinada possibilidade de apropriação do fracasso, da precariedade do ser. Mas como poderíamos nos reapropriar justamente daquilo que em sua essência é originariamente marcado pela recusa de si? Entendemos que uma avaliação honesta de tal projeto deve pautar-se antes por uma profunda e abrangente exposição da impossibilidade de uma determinação última da existência, isto é, uma determinação que deve sempre manter-se em tensão com sua precariedade. Precariedade que, por sua vez, também deu ensejo ao horizonte metafísico orientado em suas linhas mestras por uma pretensa tentativa de suplantá-la, o que só fez por aumentá-la, ainda que de maneira encoberta.

\section{Referências}

BRITO, Emilio. Heidegger et l'hymne du sacré. Louvain: Presses Universitaires, 1999.

HEIDEGGER, Martin. Aus der Erfahrung des Denkens. 2. Aufl. Frankfurt am Main: Vittorio Klostermann, 2002 [1983] (Gesamtausgabe: 13).

HEIDEGGER, Martin. Beiträge zur Philosophie (Vom Ereignis). 3. Aufl. Frankfurt am Main: Vittorio Klostermann, 2003 [1989] (Gesamtausgabe: 65).

\footnotetext{
22 "Trata-se de suportar a 'presença da falta' (Gegenwart des Fehls) em vez de querer pretensamente extirpar a carência por todos os meios" (BRITO, 1999, p. 140).

23 "Então pode ser que naquilo que em geral só aparece como decadência e destruição, como rebaixamento e declínio, se oculte algo outro e mais elevado" (HEIDEGGER, 2002, p.157).
} 
HEIDEGGER, Martin. Die Grundbegriffe der Metaphysik. Welt - Endlichkeit - Einsamkeit. 3.Aufl. Frankfurt am Main: Vittorio Klostermann, 2004 [1983] (Gesamtausgabe: 29/30).

HEIDEGGER, Martin. Die Grundprobleme der Phänomenologie. Frankfurt am Main: Vittorio Klosterman, 2005 (Klostermann Seminar: 16).

HEIDEGGER, Martin. Einführung in die Metaphysik. 6. Aufl. Tübingen: Max Niemeyer, 1998 [1953].

HEIDEGGER, Martin. Einleitung in die Philosophie. 2.Aufl. Frankfurt am Main: Vittorio Klostermann, 2001 [1996] (Gesamtausgabe: 27).

HEIDEGGER, Martin. Erläuterungen zu Hölderlins Dichtung. 6. Aufl. Frankfurt am Main: Vittorio Klostermann, 1996 [1944].

HEIDEGGER, Martin. Hölderlins Hymne “Andenken”. 2. Aufl. Frankfurt am Main: Vittorio Klostermann, 1992 [1982] (Gesamtausgabe: 52).

HEIDEGGER, Martin. Holzwege. 6. Aufl. Frankfurt am Main: Vittorio Klostermann, 1980 [1950].

HEIDEGGER, Martin. Nietzsche. Seminare 1937 und 1944. 1. Nietzsches metaphysische Grundstellung (Sein und Schein). 2. Skizzen zu Grundbegriffe des Denkens. Frankfurt am Main: Vittorio Klostermann, 2004b (Gesamtausgabe: 87).

HEIDEGGER, Martin. Parmenides. 2. Aufl. Frankfurt am Main: Vittorio Klostermann, 1992b [1982] (Gesamtausgabe: 54).

HEIDEGGER, Martin. Sein und Wahrheit. 1. Die Grundfrage der Philosophie. 2. Vom Wesen der Wahrheit. Frankfurt am Main: Vittorio Klostermann, 2001b (Gesamtausgabe: 36/37).

HEIDEGGER, Martin. Sein und Zeit. 11. Aufl. Tübingen: Max Niemeyer, 1967.

HEIDEGGER, Martin. Seminare. 2.Aufl. Frankfurt am Main: Vittorio Klostermann, 2005b [1986] (Gesamtausgabe: Bd. 15).

HEIDEGGER, Martin. Wegmarken. 3. Aufl. Frankfurt am Main: Vittorio Klostermann, 2004c [1976] (Gesamtausgabe: 9).

HÖLDERLIN, Friedrich. Reflexões. Seguidas de "Hölderlin, Tragédia e Modernidade", por Françoise Dastur. Organizado por Antônio Abranches e introduzido por Marcia de Sá Cavalcante. Trad. Antônio Abranches e Marcia de Sá Cavalcante. R.J.: Relume-Dumará, 1994.

MORUJÃO, Carlos. Verdade e Liberdade em Martin Heidegger. Lisboa: Instituto Piaget, 2000 (Col. Pensamento e Filosofia: vol. 44).

STEIN, Ernildo. Compreensão e finitude. Estrutura e movimento da interrogação heideggeriana. Ijuí: Unijuí, 2001. 